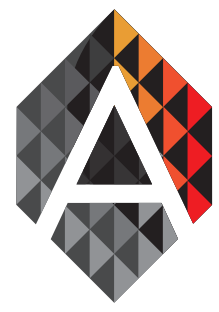

\title{
Design of a Speed Assistant to Minimize the Driver Stress
}

\author{
Victor Corcoba Magaña ${ }^{a}$, Mario Muñoz Organero ${ }^{a}$, \\ Juan Antonio Álvarez-García ${ }^{\mathrm{b}}$ \\ and Jorge Yago Fernández Rodríguez \\ ${ }^{a}$ Telematic Engineering Department, Universidad Carlos III de Madrid, 28911 Leganés, Spain \\ ${ }^{\mathrm{b}}$ Computer Languages and Systems Department, University of Seville, 41012 Seville, Spain \\ vcorcoba@it.uc3m.es, munozm@it.uc3m.es, jalvarez@us.es, jorgeyago@us.es
}

\begin{tabular}{|c|c|}
\hline KEYWORD & ABSTRACT \\
\hline $\begin{array}{l}\text { Intelligent } \\
\text { Transport System; } \\
\text { Driver Stress; } \\
\text { Driving Assistant, } \\
\text { Deep Learning; } \\
\text { Particle Swarm } \\
\text { Optimization; } \\
\text { Android; Mobile } \\
\text { Computing }\end{array}$ & $\begin{array}{l}\text { Stress is one of the most important factors in traffic accidents. When the driver is in } \\
\text { this mental state, their skills and abilities are reduced. In this paper, we propose an } \\
\text { algorithm to estimate the optimal speed to minimize stress levels on upcoming road } \\
\text { segments when driving. The prediction model is based on deep learning. The stress } \\
\text { level estimation considers the previous driver's driving behavior before reaching the } \\
\text { road section to be assessed, the road state (weather and traffic), and the previous } \\
\text { drives made by the driver. We use this algorithm to build a speed assistant. The solu- } \\
\text { tion provides an optimum average speed for each road segment that minimizes the } \\
\text { stress. A validation experiment has been conducted in a real setting using two different } \\
\text { types of vehicles. The proposal is able to predict the stress levels given the average } \\
\text { speed by } 84.20 \% \text { on average. On the other hand, the speed assistant reduces the stress } \\
\text { levels (estimated from the driver's heart rate signal) and the aggressiveness of driving } \\
\text { regardless of the vehicle type. The proposed solution is implemented on Android mo- } \\
\text { bile devices and uses a heart rate chest strap. }\end{array}$ \\
\hline
\end{tabular}

\section{Introduction}

According to many researchers, excessive speed is the cause of a large number of accidents. Therefore, it is one of the most important variables for predicting the risk of accidents and its severity. In (UK Transport Department, 2014), the authors of the report pointed out that speeding (speed higher than speed limits) is responsible for $18 \%$ of accidents in London during the year 2014, whereas travelling too fast for the road conditions caused 8 per cent of fatal accidents. Reducing average speed, results in a decrease of the number of fatalities (Lettry and Van Schagen, 2006).

Speed is a factor that is closely related to demand attention from the driver. When the speed is high, the driver has less time to make decisions. This is important when speed is not suitable for the road type (urban, rural) or road state (weather, traffic). On roads where the speed limit is high (such as motorways), safety conditions tend to be good if speed limits are not surpassed. However, if the driver exceeds the speed limit, the probability of an accident increases, especially in urban road. Authors in (Haworth and Symmons, 2001) observed that the

Victor Corcoba Magaña, Mario Muñoz Organero,

Juan Antonio Álvarez-García

and Jorge Yago Fernández Rodríguez

Design of a Speed Assistant to Minimize the Driver Stress
ADCAIJ: Advances in Distributed Computing and Articial Intelligence Journal Regular Issue, Vol. 6 N. 3 (2017), 45-56 elSSN: 2255-2863 - http://adcaij.usal.es (๑) Ediciones Universidad de Salamanca - cc BY 
risk of a pedestrian dying in an accident at impact speeds of $50 \mathrm{~km} / \mathrm{h}$ is 10 times higher than at impact speeds of $30 \mathrm{~km} / \mathrm{h}$. In addition, the critical point to survival is between $50 \mathrm{~km} / \mathrm{h}$ and $60 \mathrm{~km} / \mathrm{h}$.

Besides the vehicle speed, there are other related factors that affect safety such as sudden accelerations and decelerations and aggressive driving. 56\% of fatal accidents between 2003 and 2007 involved one or more aggressive actions (AAA Foundation, 2009), such as: suddenly changing speeds, making an improper turn or erratic lane changing. This behavior is often related to the stress of the driver.

Stress can be defined as a change from a calm state to an excitation state in order to preserve the integrity of the person. If the stress is negative, it is called «distress». This type of stress is commonly due to an increase in the workload, such as traffic density, inappropriate vehicle speed, etc. It causes irritability, lower concentration and reduces the ability to take decisions. It also shows related physical symptoms such as headache and a fast heartbeat. Stressed drivers are more likely to engage in risky behaviors and having accidents (Hill and Boyle, 2007). There are many proposals to detect stress and measure the workload (Solovey, 2014). Most of them are based on physiological features such as electromyogram, electrocardiogram, respiration, and skin conductance. Non-invasive and non-intrusive sensors are particularly interesting for measuring driver stress.

In the related literature there are many assistants that help to adapt the speed in order to maximize safety and reduce fuel consumption. These systems are called «Intelligent Speed Adaptation» (ISA). A large number of researchers have evaluated the benefits that these systems provide regarding safety and fuel consumption. The research on ISA started in 1982 when the first study of driver behavior with a variable speed limiter appeared (Saad and Malaterre, 1982). However, these solutions are still a challenge and many open questions are still to be solved. They require that the technology sufficiently matches the real-world situation. If the system does not give an accurate answer, the user stops using it. Moreover, these solutions need to acquire relevant information from the environment. This could involve the Government support in order to install sensors on the roads.

The research study in (Carsten and Tate, 2012) estimates that using a simple mandatory system, with which it would be impossible for vehicles to exceed the speed limit, $20 \%$ of injury accidents would be saved as well as $37 \%$ of fatal accidents. If the solution takes into account the environment state, the authors predicted a reduction of $36 \%$ in injury accidents and $59 \%$ in fatal accidents. Other authors have shown that accidents are minimized by $48.5 \%$, while not increasing travel time more than $2.5 \%$. In (Oei and Polak, 2002), the authors conducted a study in the Netherlands and estimated a reduction of the accidents between $25 \%$ and $30 \%$ if all vehicles use an ISA system. In (Biding and Lind, 2002), the authors made a large-scale test in Borlänge, Lidköping, Lund and Umeå during the period 1999-2002. They found that the average speed on stretches road and intersections was reduced with the use of an ISA system. Travelling times in urban areas remain unchanged on average because there is less stopping and fewer braking situations. They estimate that road injuries could be reduced by $20 \%$ in urban areas. In (Mimura et al., 2015), the authors analyzed the impact of an ISA solution when the drivers were elderly. The study analyzed information about the driving (vehicle speed and accelerator pedal) and the workload (pupil dilation method). The results showed that the proposal does not reduce the speed because elderly drivers already tend to lead below the limit of speed. However, the solution got significantly reduce mental load.

The use of ISA systems also has a positive impact on the environment. (Regan et al., 2006) shows an improvement on fuel consumption and the emission of gaseous pollutants in the zones limited to $80 \mathrm{~km} / \mathrm{h}$ (both 4\%). The authors in (Liu et al., 1999) found that the percentage of improvement was closely related to the percentage of penetration of ISA systems. They estimated that if all vehicles using the solution, fuel economy would be $8 \%$ on urban road, $3 \%$ on rural road, and $1 \%$ on highway.

In conclusion, a proper speed is important in order to reduce the number of accidents. In addition, it also influences fuel consumption and the greenhouse emissions. The suitability of ISA solutions to accurately adjust the speed has been demonstrated in many proposals. However, our aim is to estimate a speed that minimizes stress rather than reduces the consequence of that stress (traffic accidents).

The rest of the paper is organized as follows. Section 2 introduces the proposal. Section 3 describes the algorithm used to estimate the stress level given a recommended speed. In Section 4, the solution is validated with two different types of vehicles. Finally, Section 5 presents our conclusions and the future work.

Victor Corcoba Magaña, Mario Muñoz Organero,

Juan Antonio Álvarez-García

and Jorge Yago Fernández Rodríguez

Design of a Speed Assistant to Minimize the Driver Stress
ADCAIJ: Advances in Distributed Computing and Articial Intelligence Journal Regular Issue, Vol. 6 N. 3 (2017), 45-56 eISSN: 2255-2863 - http://adcaij.usal.es (c) Ediciones Universidad de Salamanca - cc BY 


\section{Our Approach}

In this work, we propose a driving assistant that estimates the optimal average speed for the next road section taking into account the driving and the stress level evaluated on the preceding road section. In addition, the algorithm considers the vehicle telemetry obtained by the driver in some of the previous drives under similar driving conditions.

The idea is that the driving assistant proposes an average speed for the upcoming road section which minimizes the driver stress and does not increase the trip time significantly. This speed does not require a sudden change in driving habits because the proposed average speed is based on the driver. The objective is to avoid one of the biggest problems of the driving assistant: frustration and impatience.

\subsection{Estimation of the optimum speed to avoid stress}

Particle Swarm Optimization (PSO) (Kennedy and Eberhart, 2012) and Deep Learning (Sun et al., 2014) are used to estimate the average speed for each section of the road. Figure 1 shows the flowchart to estimate the optimum speed. The main advantage of PSO algorithm is that it maintains multiple potential solutions at one time. We use Deep Learning techniques in order to compute the fitness function because they allow us to represent complex relationships between data. Other algorithms were tested during the test stage such as neural networks. However, deep learning obtained the highest hit ratio.

Each solution is represented by a particle in the search space. It has the following elements:

- Position: In our case is the recommended speed for reducing the stress level.

- Pbest: This is the best position on the current particle (speed that minimizes the heart rate and improves the driving style).

- Gbest: It is the best position among all particles.

- Speed: Is calculated using equation 1. It determines which will be the next speed of the particle.

$$
\mathrm{v}_{\mathrm{i}}(\mathrm{t})=\mathrm{w}^{*} \mathrm{v}_{\mathrm{i}}(\mathrm{t}-1)+\mathrm{c} 1 * \mathrm{r} 1 *\left(\operatorname{Pbest}(\mathrm{t}-1)-\mathrm{x}_{\mathrm{i}}(\mathrm{t}-1)\right)+\mathrm{c} 2 * \mathrm{r} 2 *\left(\text { Gbest- } \mathrm{x}_{\mathrm{i}}(\mathrm{t}-1)\right)
$$

where $v_{i}(t)$ is the particle's velocity at time $t, w$ is the inertia weight, $x_{i}(t)$ is the particle's position at time $t$, Pbest is the particle's individual best solution as of time $t$, and gBest $(t)$ is the swarm's best solution as of time $t, c 1$ and $\mathrm{c} 2$ are two positive constants, and $\mathrm{r} 1$ and $\mathrm{r} 2$ are random values in the range [0-1]

The particles «fly» or «swarm» evolve through the search space to find the minimum value. During each iteration of the algorithm, they are evaluated by an objective function to determine its fitness. Next position is calculated by equation 2 :

$$
\mathrm{x}_{\mathrm{i}}(\mathrm{t}+1)=\mathrm{x}_{\mathrm{i}}(\mathrm{t})+\mathrm{v}_{\mathrm{i}}(\mathrm{t}+1)
$$

where $x_{i}(t)$ is the current particle's position and $v_{i}(t+1)$ is the new velocity.

Victor Corcoba Magaña, Mario Muñoz Organero,

Juan Antonio Álvarez-García

and Jorge Yago Fernández Rodríguez

Design of a Speed Assistant to Minimize the Driver Stress
ADCAIJ: Advances in Distributed Computing and Articial Intelligence Journal Regular Issue, Vol. 6 N. 3 (2017), 45-56 elSSN: 2255-2863 - http://adcaij.usal.es (c) Ediciones Universidad de Salamanca - cC BY 


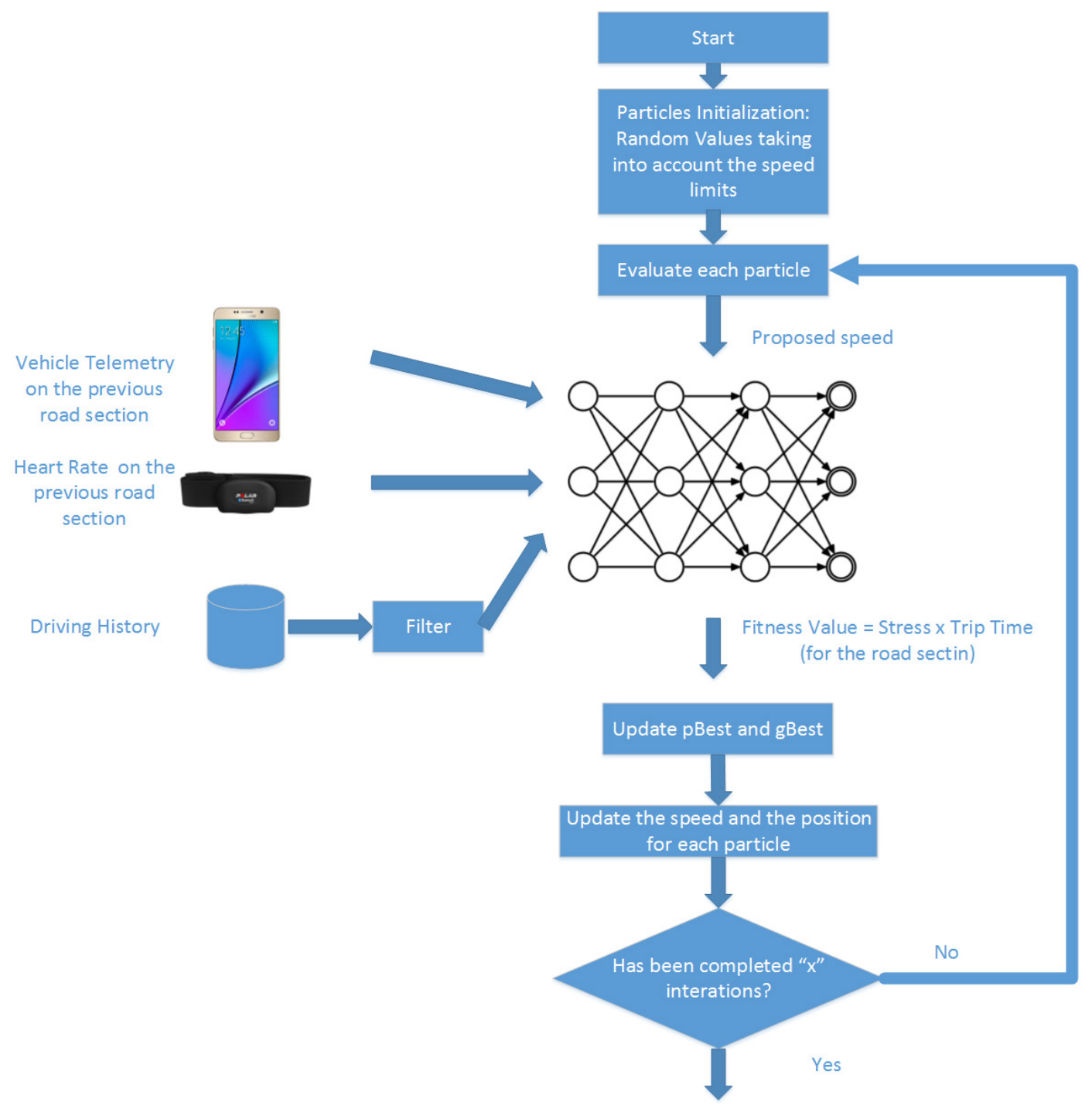

Optimal Average Speed for the next road section

Figure 1. Flowchart to estimate the optimum speed for reducing stress and fuel consumption

\subsection{Evaluation of the particles}

The fitness function is a deep learning algorithm. This type of algorithms has their origin in artificial neural networks, the main difference being the number of hidden layers and the training process. A deep learning algorithm estimates the stress level given a recommended speed (the particle position) based on:

- The driving and the stress level on the previous road section

- Telemetry samples from the next road section takes by the user other days

In figure 1, we can see that there is a filter applied to the driving history. The algorithm is trained with samples of driving that were obtained under conditions similar to the present ones. We must bear in mind that speed is a variable that depends on a large number of factors such as the traffic state or weekday. In our case, we consider the following elements to filter:

Victor Corcoba Magaña, Mario Muñoz Organero,

Juan Antonio Álvarez-García

and Jorge Yago Fernández Rodríguez

Design of a Speed Assistant to Minimize the Driver Stress
ADCAIJ: Advances in Distributed Computing and Articial Intelligence Journal Regular Issue, Vol. 6 N. 3 (2017), 45-56 elSSN: 2255-2863 - http://adcaij.usal.es (c) Ediciones Universidad de Salamanca - CC BY 
- Weather State: The number of vehicles on the road grows when the weather conditions are bad, increasing the likelihood of traffic incidents. Moreover, the roll coefficient changes. Therefore, the advice has to take into account that factor. In addition, many studies highlight that when it is hot, the fatigue related symptoms tend to appear before. On the other hand, the cognitive capacity of the driver worsens when it is cold.

- Traffic State: When traffic is heavy, the stress level increases. In these cases, the vehicle speed must be adjusted in order to avoid accelerations and decelerations.

- Time: Fuel consumption is increased at rush hours. The driver has to accelerate and slow down more frequently. In addition, the engine is switched on during more time. This situation causes stress, increasing the accidents risk. On the other hand, night driving maximizes the likelihood of suffering drowsiness despite he or she has previously slept. This is due to the sleep cycle (circadian rhythm). Therefore, we have to take into account the particular time of the day when we estimate the optimum speed.

- Weekday: The rush hour depends on the day. For instance, it is common that the average speed is higher on weekends because there is less traffic. If the road conditions are good, the system should recommend an average speed high enough to avoid the frustration of the driver.

The Deep Belief Network that we have defined in our proposal has the following input variables:

- Recommended average speed $(\mathrm{km} / \mathrm{h})$ : It is the vehicle speed proposed by the PSO algorithm. If the speed is too high, the stress will increase because the driver has less time to make decisions. On the contrary, if the speed is abnormally low, fuel consumption will increase because the engine will be running more time. In addition, it may cause traffic incidents and the stress level from road users would be higher.

- Positive Kinetic Energy $\left(\mathrm{m} / \mathrm{s}^{2}\right)$ : It measures the aggressiveness of driving and depends on the frequency and intensity of positive accelerations (González R et al., 2014). A low value means that the driver is not stressed and drives smoothly. The value is calculated using the following equation:

$$
P K E=\frac{\sum\left(v_{i}-v_{i-1}\right)^{2}}{d} ; v_{i-1}<v_{i}
$$

where $v_{i}$ is the vehicle speed $(\mathrm{m} / \mathrm{s})$ and $d$ is the trip distance (meters) between $v_{i}$ and $v_{i-1}$.

- Average Acceleration $\left(\mathrm{m} / \mathrm{s}^{2}\right)$ : The acceleration (positive and negative) may indicate the presence of stress or fatigue. These actions increase the likelihood of traffic accidents and fuel consumption.

- Speed $(\mathrm{Km} / \mathrm{h})$ : This variable allows us to model the driver behavior. For each section, we consider the following measures statistics: minimum, medium, maximum, average, and standard deviation.

- Average Heart Rate (b.p.m): Heart Rate signals are employed as an indicator of ANS neuropathy for normal, fatigued and drowsy states because the ANS is influenced by the sympathetic nervous system and parasympathetic nervous system. This indicator is not intrusive. A high heart rate means the driver has stress.

The output of the deep learning algorithm will be an estimate of the stress level when the driver drives at « $\mathrm{x} » \mathrm{~km} / \mathrm{h}$ on average. The output can take the following values:

\begin{tabular}{|c|c|c|}
\hline Low Stress & Normal Stress & High Stress \\
\hline 0.5 & 1 & 1.5 \\
\hline
\end{tabular}

The final value of the fitness function is given by the value of estimated stress and the time required in order to complete the road section. The goal is to find a velocity that balances stress level and travel time, staying safe on the road.

Victor Corcoba Magaña, Mario Muñoz Organero,

Juan Antonio Álvarez-García

and Jorge Yago Fernández Rodríguez

Design of a Speed Assistant to Minimize the Driver Stress
ADCAIJ: Advances in Distributed Computing and Articial Intelligence Journal Regular Issue, Vol. 6 N. 3 (2017), 45-56 elSSN: 2255-2863 - http://adcaij.usal.es (c) Ediciones Universidad de Salamanca - cC BY 


\section{Deep Learning}

A deep-belief network (DBN) [29] is defined as a stack of restricted Boltzmann machines (RBM), in which each RBM layer communicates with both the previous and subsequent layers. The nodes of any single layer do not communicate with each other laterally. The end of DBN is a classifier. We employ gradient-descent algorithm to revise the weight matrix of the whole network. The error is propagated in the opposite direction. Therefore, the parameters of RBMs change slightly. DBN has the following steps:

Layer-wise Unsupervised Learning: We train the first RBM using the original data without the labels (unsupervised) and fixing up the parameters of this RBM. Then, the first layer configuration is frozen. We train the second layer using the output of the first layer. Finally, we get a DBN with several layers, whose parameters are appropriate to extract the features of data. This method avoids the overfitting. In addition, we can take advantage of unlabelled data.

Fine-Turning: We unfreeze all weights, and train full DBN with supervised model (SoftMax classifier) to fine-tune weights. Gradient-descent algorithm is employed to update the weight matrix of the whole network. This solution avoids drastic changes because the error is propagated in the opposite direction.

\section{Restricted Boltzmann Machine (RBM)}

Restricted Boltzmann Machines are bipartite graphs with a layer of «hidden» neurons and a layer of «visible» neurons, without connections between neurons in the same layer. Each node represents a random variable and each edge a dependency between variables that connects.

We employ energy function (E) and probability distribution to describe a RBM. The energy of a configuration (pair of boolean vectors) (v,h) is defined as:

$$
E(v, h)=-\sum_{i} a_{i} v_{i}-\sum_{j} b_{j} h_{j}-\sum_{i} \sum_{j} v_{i} w_{i, j} h_{j}
$$

where $a_{i}$ is the bias weight (offset) for the visible unit $v_{i}, b_{j}$ is the bias weight for the hidden unit $h_{j}$, and $w_{i, j}$ the weight associated with the connection between hidden unit $h_{j}$ and visible unit $v_{i}$.

Probability Distribution:

$$
p(v, h)=\frac{1}{z} e^{-E(v, h)}
$$

where $\mathrm{Z}$ is a partition function defined as the sum of $e^{-E(y, h)}$ over all possible configurations. The aim is to ensure the probability distribution sums to 1 .

Through summation we can get the marginal distribution of visible layer $\boldsymbol{v}$ :

$$
p(v)=\frac{1}{Z} \sum_{h} e^{-E(v, h)}
$$

\section{SoftMax Classifier}

There are a set of training samples such as: $\left\{\left(\mathrm{x}^{1}, \mathrm{y}^{1}\right),\left(\mathrm{x}^{2}, \mathrm{y}^{2}\right), \ldots,\left(\mathrm{x}^{\mathrm{m}}, \mathrm{y}^{\mathrm{m}}\right)\right\}, \mathrm{y}^{\mathrm{i}} \in\{1,2, \ldots \mathrm{m}\}$. The classifier is used in order to estimate the probability that $\mathrm{x}$ is a sample of $\mathrm{j}$ class. The activation function is:

$$
h_{\theta}(x)=\left[\begin{array}{c}
P(y=1 \mid x, \theta) \\
P(y=2 \mid x, \theta) \\
\cdots \\
P(y=k \mid x, \theta)
\end{array}\right]=\frac{1}{Z}\left[\begin{array}{c}
e^{\theta_{1} \times X} \\
e^{\theta_{2} \times X} \\
\ldots \\
e^{\theta_{k} \times X}
\end{array}\right]
$$

Where $Z=\sum e^{\theta_{j} \times X}$ is normalization factor.

The cost function to train the classifier is:

Victor Corcoba Magaña, Mario Muñoz Organero,

Juan Antonio Álvarez-García

and Jorge Yago Fernández Rodríguez

Design of a Speed Assistant to Minimize the Driver Stress
ADCAIJ: Advances in Distributed Computing and Articial Intelligence Journal Regular Issue, Vol. 6 N. 3 (2017), 45-56 elSSN: 2255-2863 - http://adcaij.usal.es (C) Ediciones Universidad de Salamanca - CC BY 


$$
J(\theta)=-\frac{1}{m}\left[\sum_{i=1}^{m} \sum_{j=1}^{n} 1\left\{y^{(i}\right\} \log \frac{e^{\theta_{j}^{T} x(i)}}{\sum_{s=0}^{n} \theta_{S}^{T} x(i)}\right]
$$

In the equation, $1\{(i)=j\}$ is indicative function, whose value is 1 when $y(i)=j$ and 0 when not. The aim is to minimize the cost function adjusting the parameters. We employ gradient-descent algorithm to make this task.

\section{Experimental Design}

\subsection{Validation of the stress prediction algorithm}

The speed assistant was deployed on a Galaxy Note 4 mobile device. This device supports Bluetooth Low Energy. Heart Rate was monitored using GEONAUTE ${ }^{1}$. In order to validate the algorithm, we employed five datasets with 100 driving samples. Table 1 describes the dataset features. Each column captures the number of samples where the driver stress is low, normal and high, respectively. The driving samples were obtained on real tests. Each dataset contains the vehicle telemetry and the heart rate obtained in the current road section and the previous road section. Driving tests were performed in Seville. Trip distance was $23 \mathrm{~km}$. This track has highway, secondary road, and urban road segments. The route was divided into sections of 500 meters. We have chosen this length after making several tests with the datasets. Figure 2 captures the entire route (green line). We chose five road sections to analyze the algorithm. The vehicle was a Seat Ibiza Sport 1.9 TDI (2008). Tests were performed under similar road conditions.

Table 1. Dataset Features employed to validate the algorithm

\begin{tabular}{|l|r|r|r|r|}
\hline & Low Stress & Normal Stress & \multicolumn{1}{c|}{ High Stress } & \multicolumn{1}{c|}{ Total } \\
\hline Dataset 1 & 58 & 30 & 12 & 100 \\
\hline Dataset 2 & 18 & 53 & 29 & 100 \\
\hline Dataset 3 & 36 & 28 & 36 & 100 \\
\hline Dataset 4 & 34 & 21 & 45 & 100 \\
\hline Dataset 5 & 35 & 43 & 22 & 100 \\
\hline
\end{tabular}

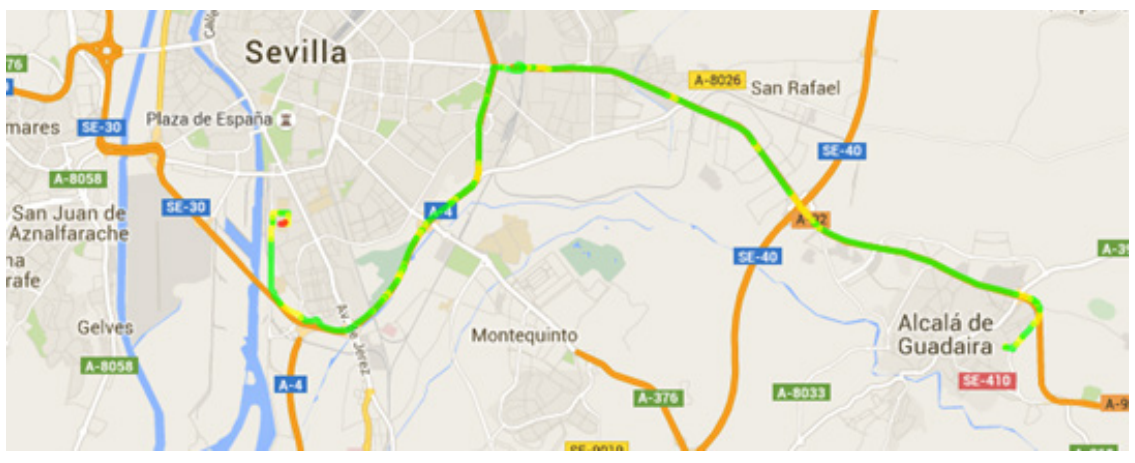

Figure 2. Route for the driving tests

1. http://www.geonaute.es/cinturon-cardiofrecuencimetro-bluetooth-smart-40-id 8288269 .

Victor Corcoba Magaña, Mario Muñoz Organero, Juan Antonio Álvarez-García and Jorge Yago Fernández Rodríguez

Design of a Speed Assistant to Minimize the Driver Stress
ADCAIJ: Advances in Distributed Computing and Articial Intelligence Journal Regular Issue, Vol. 6 N. 3 (2017), 45-56 eISSN: 2255-2863 - http://adcaij.usal.es (c) Ediciones Universidad de Salamanca - cC BY 
Table 2 presents the results (Mean squared error and hit rate) of the algorithm considering the five datasets and using 10 fold cross validation. The proposal is able to predict the stress given the average speed by 84.20 $\%$ on average. The deep learning algorithm was run with 3 hidden layers, 200 units per layer and 300 epochs.

Table 2. Results of the 10 fold cross validation using the proposal

\begin{tabular}{|l|c|c|}
\hline & MSE & Hit Rate (\%) \\
\hline Dataset 1 & 0.156802 & $84 \%$ \\
\hline Dataset 2 & 0.131412 & $85 \%$ \\
\hline Dataset 3 & 0.111304 & $89 \%$ \\
\hline Dataset 4 & 0.071342 & $92 \%$ \\
\hline Dataset 5 & 0.283674 & $71 \%$ \\
\hline
\end{tabular}

\subsection{Analysis of the Speed Assistant}

The proposal was validated using two different types of vehicles: a car and a motorbike. In the first case, the car and the route was the same as in the previous section (Validation of stress prediction algorithm). For the second case, a driver used a motorbike (Kawasaki vn900 classic) to travel on an urban route in Madrid (Spain). The trip distance was $9.7 \mathrm{~km}$. The track was divided into sections of 500 meters as in the first scenario. This motorcyclist made 22 different drives on the same route (eleven with driving assistant and eleven without driving assistant). Table 3 captures the features of the motorcycle.

Table 3. Features of a Kawasaki vn900 classic

\begin{tabular}{|c|c|}
\hline Feature & Value \\
\hline Engine & $\begin{array}{c}\text { 4-Stroke, Liquid-Cooled, } \\
\text { SOHC, 4-Valve Cylinder } \\
\text { Head, V-Twin }\end{array}$ \\
\hline Displacement & $903 \mathrm{cc}$ \\
\hline Bore x Stroke & $88 \times 74.2 \mathrm{~mm}$ \\
\hline Compression Ratio & $9.5: 1$ \\
\hline Fuel Injection & $\begin{array}{c}\text { EFI with } 34 \mathrm{~mm} \text { Keihin } \\
\text { Throttle Bodies (X2) }\end{array}$ \\
\hline Ignition & $\begin{array}{c}\text { TCBI with Digital } \\
\text { Advance }\end{array}$ \\
\hline FuelTank Capacity & 20 liters \\
\hline Weight & $282 \mathrm{Kg}$ \\
\hline
\end{tabular}

Figure 3 shows the average heart rate obtained by the driver on different road sections without and with the speed assistant. The heart rate decreases by $14.94 \%$ on average taking into account all driving samples in the car case. On the other hand, this variable was improved by $8.56 \%$ in the motorbike case (Figure 4 ). The heart rate value is influenced by the sympathetic nervous system and parasympathetic nervous system. A low value means that the driver is not stressed. The motorcyclist body is more exposed than in the case of the car driver. The consequence is that the stress is higher under the same conditions.

Victor Corcoba Magaña, Mario Muñoz Organero,

Juan Antonio Álvarez-García

and Jorge Yago Fernández Rodríguez

Design of a Speed Assistant to Minimize the Driver Stress
ADCAIJ: Advances in Distributed Computing and Articial Intelligence Journal Regular Issue, Vol. 6 N. 3 (2017), 45-56 elSSN: 2255-2863 - http://adcaij.usal.es (c) Ediciones Universidad de Salamanca - CC BY 


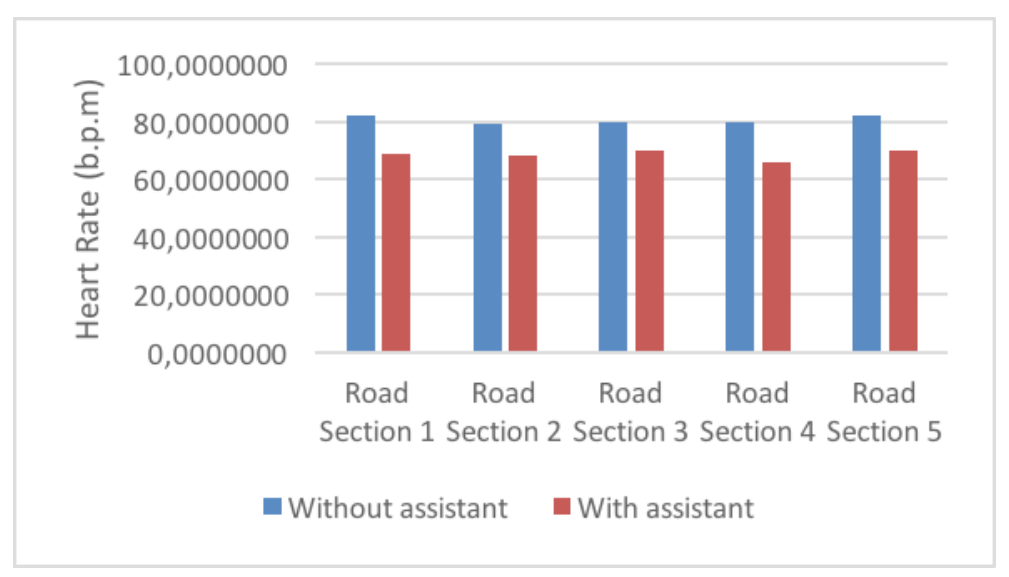

Figure 3. Average heart rate (b.p.m) using the speed assistant in a car

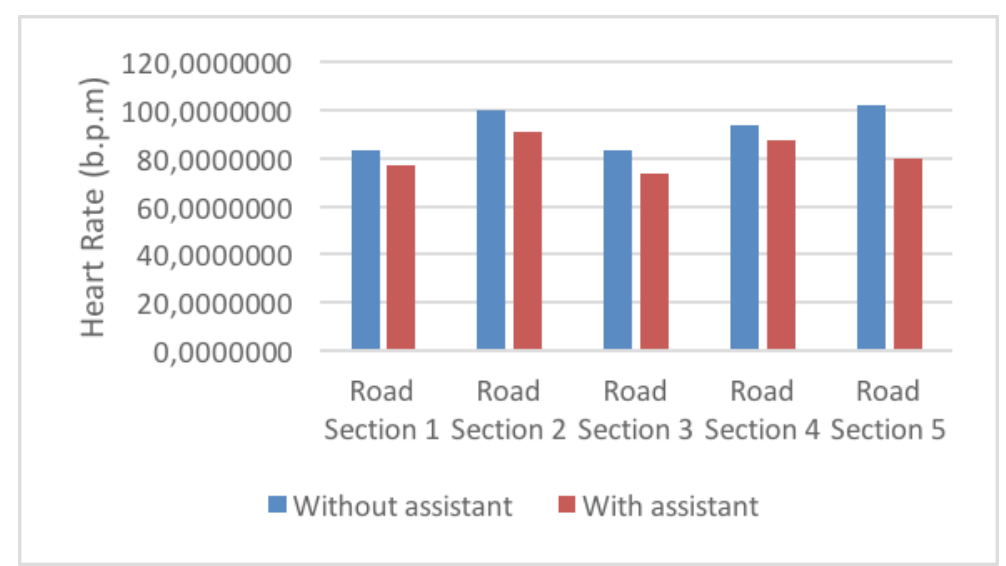

Figure 4. Average heart rate (b.p.m) using the speed assistant in a motorbike

Figure 5 illustrates the positive kinetic energy obtained by the driver when driving with and without the speed assistant. Figure 6 captures this variable when the solution was installed in a motorbike. This variable measures the aggressiveness of driving and depends on the frequency and intensity of positive acceleration. A low value means that the driving is not aggressive. A smoother driving saves more fuel and reduces the stress. The positive kinetic energy decreases by $36.97 \%$ on average when the driver uses the proposal. On the other hand, this variable was minimized by $41 \%$ in the case of motorcyclist. Furthermore, we can observe that the PKE value from motorcyclist is always higher than the value obtained with the car.

Victor Corcoba Magaña, Mario Muñoz Organero, Juan Antonio Álvarez-García and Jorge Yago Fernández Rodríguez Design of a Speed Assistant to Minimize the Driver Stress
ADCAIJ: Advances in Distributed Computing and Articial Intelligence Journal Regular Issue, Vol. 6 N. 3 (2017), 45-56 elSSN: 2255-2863 - http://adcaij.usal.es (c) Ediciones Universidad de Salamanca - cC BY 


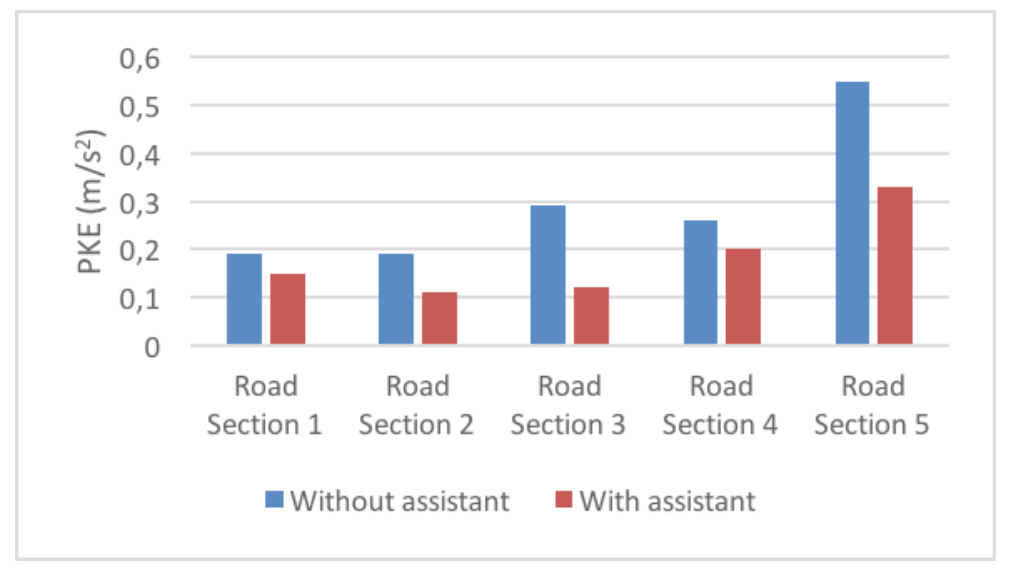

Figure 5. Positive Kinetic Energy $\left(\mathrm{m} / \mathrm{s}^{2}\right)$ using the speed assistant in a car

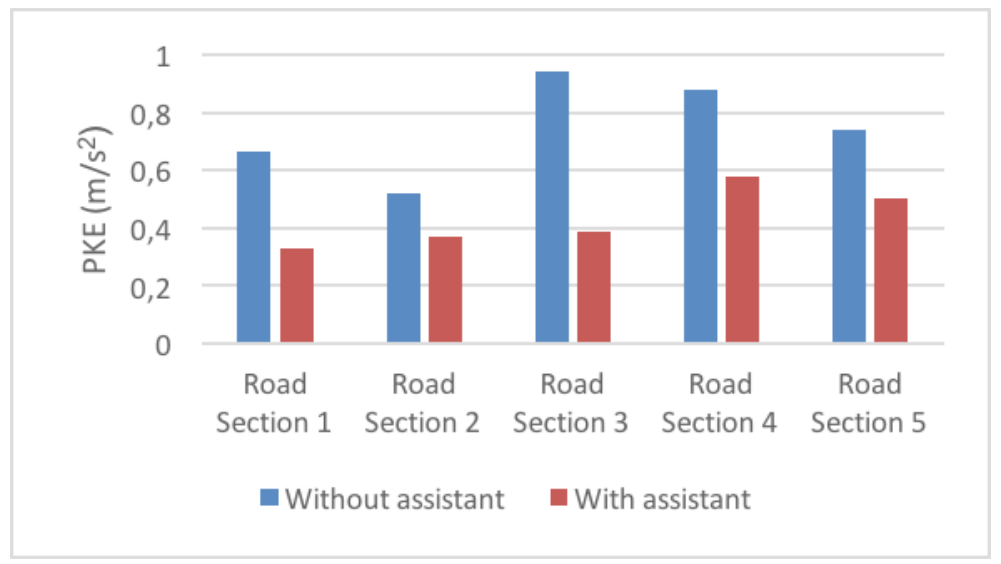

Figure 6. Positive Kinetic Energy $\left(\mathrm{m} / \mathrm{s}^{2}\right)$ using the speed assistant in a motorbike

Figure 7 shows the average standard deviation of vehicle speed for each road section. Following the recommended speed provided by the solution, standard deviation is reduced $37.09 \%$ on average. On the other hand, this variable was minimized by $23.38 \%$ in the motorbike scenario (Figure 8 ).

If the user has to change the speed frequently, work load and fuel consumption will increase. This happens when the driver does not adjust the speed properly. When a vehicle is accelerating, it is necessary to overcome a force proportional to vehicle mass and the acceleration.

During acceleration, higher acceleration or vehicle mass means more demand of traction force on the wheel, and therefore, an increase in fuel consumption. After reaching the desired speed, fuel consumption is decreased because the acceleration resistance is zero. For this reason, the driver must avoid changing vehicle speed whenever possible.

Victor Corcoba Magaña, Mario Muñoz Organero,

Juan Antonio Álvarez-García

and Jorge Yago Fernández Rodríguez

Design of a Speed Assistant to Minimize the Driver Stress
ADCAIJ: Advances in Distributed Computing and Articial Intelligence Journal Regular Issue, Vol. 6 N. 3 (2017), 45-56 eISSN: 2255-2863 - http://adcaij.usal.es (c) Ediciones Universidad de Salamanca - cC BY 


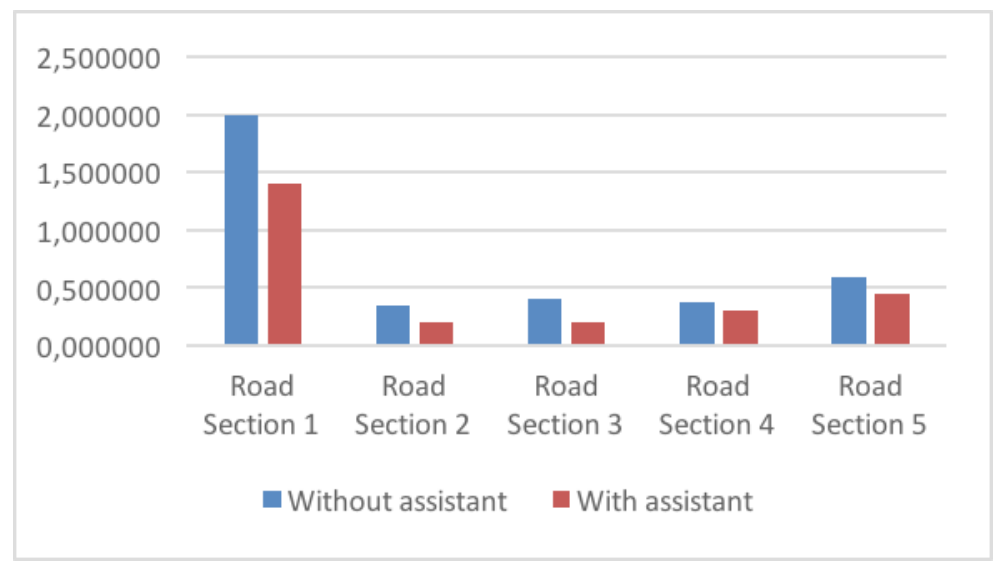

Figure 7. Standard Deviation of Vehicle Speed using the speed assistant in a car

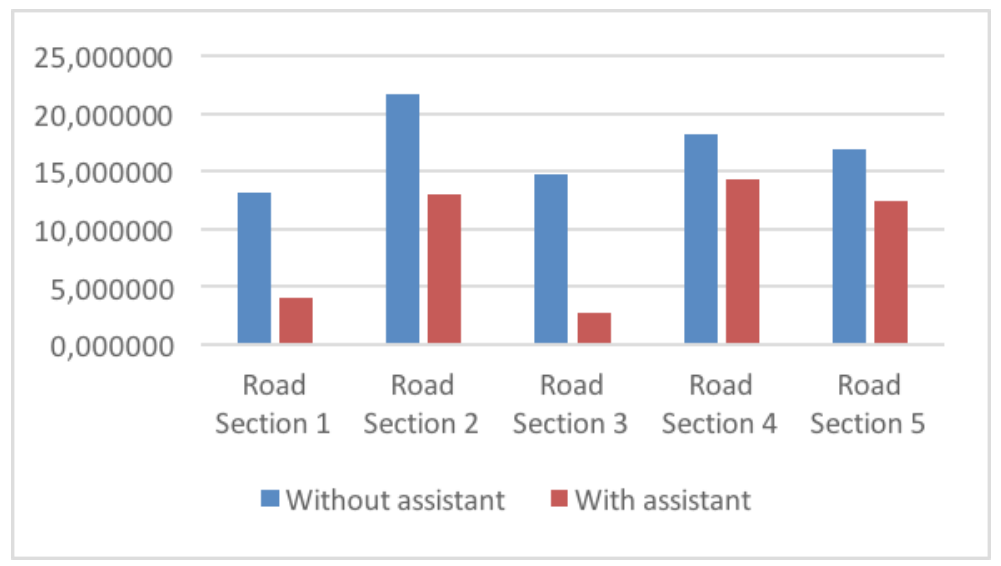

Figure 8. Standard Deviation of Vehicle Speed using the speed assistant in a motorbike

\section{Conclusions and future work}

In this paper, we have proposed an algorithm to estimate the driver stress given speed and heart rate for a road section. The goal is to prevent stress and dangerous situations, based on the current driving context, taking data from road conditions (weather and traffic), time, and previous driving. In this paper, we present a speed assistant that uses the driving context, deep learning technics along with Particle Swarm Optimization (PSO) to calculate a speed that minimizes the stress without increasing the trip time. The results show a significant improvement in the driving style and the driver stress with any type of vehicle (car and motorbike).

As future work, we want to validate the algorithm with more users and more routes. It would also be interesting to analyze the effect that the solution has in the stress of the other road users. In addition, we want to introduce new variables to improve the prediction model such as previous stress, working time, sleeping time, and quality of sleep.

Victor Corcoba Magaña, Mario Muñoz Organero,

Juan Antonio Álvarez-García

and Jorge Yago Fernández Rodríguez

Design of a Speed Assistant to Minimize the Driver Stress
ADCAIJ: Advances in Distributed Computing and Articial Intelligence Journal Regular Issue, Vol. 6 N. 3 (2017), 45-56 eISSN: 2255-2863 - http://adcaij.usal.es (c) Ediciones Universidad de Salamanca - cC BY 


\section{Acknowledgments}

The research leading to these results has received funding from the «HERMES-SMART DRIVER/CITIZEN» projects TIN2013-46801-C4-2-R /1-R funded by the Spanish MINECO, from the grant PRX15/00036 from the Ministerio de Educación Cultura y Deporte.

\section{References}

AAAFoundation, 2009. Aggressive driving: Research update. April 2009. Last access: October 2015. Available at http://www.aaafoundation.org/pdf/AggressiveDrivingResearchUpdate2009.pdf.

Biding T., and Lind G., 2002. Intelligent Speed Adaptation (ISA): Results of Large Scale Trials in Borlänge, Lidköping, Lund and Umeå during the Period 1999-2002. Publication 2002:89 E Swedish National Road Administration, Borlänge, Sweden (2002).

Carsten, O. M. J. and Tate, F. N., 2005) «Intelligent speed adaptation: accident savings and cost-benefit analysis,» Accident Anal. Prev., vol. 37, no. 3, pp. 407-416, May 2005.

Frank F., Carsten O., and Tate F., 2012. «How much benefit does Intelligent Speed Adaptation deliver: An analysis of its potential contribution to safety and environment». Accident Analysis \& Prevention 48 (2012): 63-72.

González R. et al., 2014 «Modeling and detecting aggressiveness from driving signals». Intelligent Transportation Systems, IEEE Transactions on 15.4 (2014): 1419-1428.

Haworth, N., and Symmons M., 2001. «The relationship between fuel economy and safety outcomes,» Monash Univ., Melbourne, VIC, Australia, 2001.

Hill, J.D., and Boyle, L.N., 2007. Driver stress as influenced by driving maneuvers and road-way conditions. Transportation Research Part F: Traffic Psychology and Behaviour, 2007. 10(3): p. 177-186.

Kennedy, J., Eberhart R., 1995. «Particle swarm optimization. Neural Networks». Proceedings, IEEE International Conference on, vol.4, no., pp.1942, 1948 vol.4, Nov/Dec 1995. doi: 10.1109/ICNN.1995.488968.

Letty, A., and Van Schagen, I., 2006. «Driving speed and the risk of road crashes: A review». Accident Analysis \& Prevention 38.2 (2006): 215-224. 5.

Liu, R., Tate, J., Boddy, R., 1999. Simulation Modelling on the Network Effects of EVSC. Deliverable 11.3 of External Vehicle Speed Control Project. Institute for Transport Studies, University of Leeds, UK.

Mimura, Y., Obayashi, F., Ono, T., Nakatani, S., Ando, R., Kozuka, K., \& Ozawa, S., 2015. Effects of Intelligent Speed Adaptation on Elderly Drivers' Driving Behaviors and Mental Workloads. International Journal of Intelligent Transportation Systems Research, 1-10.

Oei H. and Polak P., «Intelligent Speed Adaptation (ISA) and Road Safety», Journal of International Association of Traffic and Safety Sciences (IATSS) Research, Volume 26, No. 2, pp. 45-51, 2002.

Regan, M., Triggs, T., Young, K., Tomasevic, N., Mitsopoulos, E., Stephan, K., Tingvall, C., 2006. «On-road evaluation of intelligent speed adaptation, following distance warning and seat belt reminder systems: Final Results of the Australian TAC SafeVehicle Project».MUARC Report No. 253, Clayton.

Solovey, E. T., et al. «Classifying driver workload using physiological and driving performance data: Two field studies». Proceedings of the SIGCHI Conference on Hu-man Factors in Computing Systems. ACM, 2014. [x2]

Saad, F., and Malaterre, G., 1982. La Régulation de la Vitesse: Analyse des Aides au Contrôle de la Vitesse. Internal Report, ONSER, France.

Sun $\mathrm{N}$ et al., 2014. «Person/vehicle classification based on deep belief networks,» in Natural Computation (ICNC), 2014 10th Interna-tional Conference on , vol., no., pp.113-117, 19-21 Aug. 2014. doi: 10.1109/ ICNC.2014.6975819.

UK Transport Department, 2014. Department for Transport. Reported road casualties in Great Britain: main results 2014 https:/www.gov.uk/government/uploads/system/uploads/attachment data/file/438040/reported-road-casualties-in-great-britain-main-results-2014-release.pdf.

Victor Corcoba Magaña, Mario Muñoz Organero,

Juan Antonio Álvarez-García

and Jorge Yago Fernández Rodríguez

Design of a Speed Assistant to Minimize the Driver Stress
ADCAIJ: Advances in Distributed Computing and Articial Intelligence Journal Regular Issue, Vol. 6 N. 3 (2017), 45-56 eISSN: 2255-2863 - http://adcaij.usal.es (c) Ediciones Universidad de Salamanca - CC BY 